\title{
И.С. Преображенская
}

\author{
Кафедра нервных болезней лечебного факультета ГБОУ ВПО Первого МГМУ им. И.М. Сеченова
}

\section{Деменция с тельцами Леви:}

\section{клинические проявления, диагностика и лечение}

\begin{abstract}
Деменция с тельцами Леви (ДТЛ) - заболевание, выделенное из группы сенильной деменции в 90-е годы прошлого века. В статье подробно обсуждаются патогенез, патоморфология и клинические проявления данного заболевания, а также возможная связь симптомов болезни и особенностей распространения нейродегенеративного процесса.

Подробно описаны психические нарушения при ДТЛ, возможные причины из развития, связь галлюциноза с поражением церебральных неспецифических систем и медиаторной недостаточностью. Приведены результаты лечения ДТЛ препаратами базовой симптоматической терапии. Подробно описаны результаты клинического исследования, посвященного активности акатинола мемантина у пациентов с ДТЛ.
\end{abstract}

Ключевые слова: деменция с тельцами Леви, симптомы, диагностика, лечение. Контакты: Ирина Сергеевна Преображенская IrinaSP2@yandex.ru

\author{
Lewy body dementia: clinical manifestations, diagnosis, and treatment \\ I.S. Preobrazhenskaya \\ Department of Nervous Diseases, Faculty of Therapeutics, I.M. Sechenov First Moscow Medical University
}

Lewy body dementia (LBD) is a disease that was separated from a group of senile dementia in the 1990s. The paper details the pathogenesis, pathomorphology, and clinical manifestations of the disease, as well as a possible association of its symptoms with the specific features of the extent of the neurodegenerative process.

It also fully describes mental disorders in $L B D$, their possible causes, an association of hallucinosis with lesion of nonspecific cerebral systems and mediator failure. The results of LBD treatment with basic symptomatic therapy are given. The results of the clinical trial of the activity of akatinol memantine in the patients with $L B D$ are described in detail.

Key words: Lewy body dementia, symptoms, diagnosis, treatment. Contact: Irina Sergeyevna Preobrazhenskaya IrinaSP2@yandex.ru

Клинические и патоморфологические проявления деменции с тельцами Леви (ДТЛ) описаны недавно и до сих пор активно обсуждаются, как и диагностика, и лечение этого заболевания. Вероятно, ДТЛ можно отнести к наиболее трудным для лечения нейродегенеративным поражениям головного мозга.

Первое описание ДТЛ датировано 1950 г. и принадлежит группе японских исследователей, которые наблюдали несколько пациентов, страдавших сенильной деменцией с необычными клиническими и морфологическими проявлениями [1]. Деменция была сходна с таковой при болезни Альцгеймера (БА), но сочеталась с психическими нарушениями, наиболее часто со зрительными и слуховыми галлюцинациями, возникающими уже в дебюте заболевания. Для этих пациентов были характерны наличие экстрапирамидных симптомов - постурального тремора, тремора покоя, общей замедленности, а также диффузное распространение телец Леви (ТЛ) в подкорковых образованиях и нейронах коры головного мозга. К сожалению, описав клинические и морфологические изменения, типичные для ДТЛ, исследователи сделали неправильный вывод. У части пациентов были обнаружены морфологические изменения, типичные для БА, - сенильные бляшки и нейрофибриллярные сплетения. Вследствие этого сделано предположение, что такая деменция является результатом альцгеймеровского процесса и сочетается с независимо развивающимся паркинсонизмом. Таким образом, выделение ДТЛ в самостоятельную нозологическую единицу было отложено более чем на 40 лет.

В 1980 г. K. Kosaka и E. Iseki [2] представили описание клинико-морфологического случая, который называли «сенильной деменцией с тельцами Леви». Это описание очень напоминало представленные ранее: деменция, схожая с таковой при БА, сочетающаяся с паркинсонизмом и психическими расстройствами. При морфологическом анализе выявлено диффузное распространение ТЛ в подкорковых и корковых структурах. Однако в отличие от предыдущих исследователей K. Kosaka был уверен, что мозг пациента чист от амилоидных отложений, и связал как паркинсонизм, как и деменцию с дегенеративным поражением, отличным от наблюдающегося при БА.

В дальнейшие 10 лет появилось множество публикаций, подтверждающих мнение K. Kosaka [3-7]. Исследователи во всем мире сообщали о пациентах с похожими клиническими и патоморфологическими проявлениями.

Из-за отсутствия единого названия и клинических критериев предположительно нового заболевания попытка системного анализа данных оказалась неудачной, как и попытка создания клинико-морфологических критериев заболевания. Однако впоследствии выяснилось, что предложенные критерии ДТЛ [8] обладали низкой чувствительностью и специфичностью. К 1996 г. появилось достаточно 
клинических, нейрохимических, нейровизуализационных и патоморфологических данных, что послужило основанием для проведения первого международного симпозиума по ДТЛ [9]. На этом симпозиуме достигнуто соглашение, что ДТЛ - независимое, самостоятельное и отличное от других заболевание, принято международное название болезни и разработаны его диагностические критерии, которые используются и в настоящее время (табл. 1). Последующие 5 лет были посвящены оценке чувствительности и специфичности этих диагностических критериев. Показано, что клинический диагноз вероятной ДТЛ, установленный с помощью этих критериев, соответствует патоморфологическому диагнозу более чем в $85 \%$ случаев $[10,11]$. Таким образом, диагноз ДТЛ может быть установлен прижизненно, без обязательного патоморфологического подтверждения.

В дальнейшем критерии ДТЛ подвергались некоторой модификации. В раздел «Дополнительные симптомы» добавлены периферическая вегетативная недостаточность, нарушение сна и отсутствие фазы быстрых движений глаз (rapid eye movement, REM). Время между развитием паркинсонизма и деменции увеличено. Так, если в первой редакции оно составляло 1 год, то в настоящее время диагноз ДТЛ может быть установлен, если деменция развилась в течение 3 лет с момента возникновения симптомов паркинсонизма [12].

Частота ДТЛ среди всех причин деменции составляет от 7 до 30\% [8, 13, 14]. На первых этапах исследования, вероятно, имела место как низкая, так и чрезмерная диагностика заболевания: в части случаев ДТЛ расценивалась как БА, болезнь Паркинсона (БП) с деменцией, супрануклеарный паралич. Вместе с тем в ряде случаев пациентам с сочетанным сосудистым и нейродегенеративным поражением головного мозга, в клинической картине у которых наблюдались деменция и психические расстройства, а иногда и общая замедленность, ошибочно ставили диагноз ДТЛ. Повсеместное внедрение критериев ДТЛ позволило более точно оценить частоту этого заболевания. Было показано, что ДТЛ развивается примерно так же часто, как сосудистая деменция, а может быть, даже чаще. Встречаемость ДТЛ среди деменций составляет 10-15\% [12, 15-18].

Морфология ДТЛ, несмотря на однозначность, вызывала многочисленные споры. Она была описана намного раньше, чем приняты критерии ДТЛ. В 1913 г. немецкий невролог, психиатр и морфолог Ф. Леви описал внутрицитоплазматические интранейрональные включения в ряде подкорковых структур у пациентов с БП. «Они (ТЛ. Прим. автора) были единственными морфологическими изменениями, которые были обнаружены мною у всех исследованных пациентов на всех стадиях развития патологического процесса» [1, 19]. В 1916 г. Л.А. Третьяков в серии экспериментов подтвердил вывод Леви о том, что ука- занные включения являются типичным морфологическим признаком БП и предложил название «тельца Леви». Впоследствии Ф. Леви обнаружил указанные изменения у пациентов с сочетанием БП и деменции, с изолированной деменцией, с психическими нарушениями и деменцией и просто у пожилых пациентов и подверг сомнению свое заключение о том, что эти изменения типичны для БП. Сегодня эти результаты более понятны, поскольку ТЛ отражают патологический процесс, который развивается при заболеваниях, отнесенных к отдельному классу синуклеинопатий. Основанием для этого названия стали особенности строения ТЛ, которые состоят преимущественно из измененного альфа-синуклеина и убиквитина [5, 20]. Морфология, типичная для ДТЛ, отмечается также при БП, при сочетании БП и деменции, при мультисистемной атрофии (МСА) и первичной прогрессирующей вегетативной недостаточности. Сходство морфологии и симптомов этих заболеваний, выраженных, однако, в разной степени, даже послужило основанием для предложения объединить их в одну группу - болезни диффузных ТЛ [1].

Локализация патологических изменений при разных синуклеинопатиях отличается. Так, при БП отмечается преимущественное отложение ТЛ в нейронах черной субстанции. При ДТЛ нейродегенеративный процесс затрагивает практически все подкорковые структуры - черную субстанцию, голубое пятно, дорзальное ядро блуждающего нерва, базальное ядро Мейнерта, гипоталамус. В меньшей степени нейродегенеративный процесс распространяется на кору височных, лобных и теменных долей и в еще меньшей степени - на кору затылочных отделов головного мозга [7, 15, 20]. Эти особенности распространения нейродегенеративного процесса обусловливают полимедиаторный дефицит, характерный для данного заболевания (поражение ацетилхолинергической, дофаминергической, серотонинергической и норадреналинергической систем), и всегда вызывали 
удивление исследователей. Так, известно, что наиболее выраженным симптомом ДТЛ являются грубые зрительнопространственные нарушения, в то время как кора затылочных отделов поражается в наименьшей степени.

Патогенез ДТЛ имеет много общего с патогенезом других церебральных дегенеративных процессов. Так, гибель церебральных нейронов при ДТЛ реализуется путем апоптоза, или программированной клеточной смерти, в результате активации генов-индукторов и/или угнетения генов-ингибиторов апоптоза [17, 21]. Определенную роль при этом могут играть снижение активности антиокислительных церебральных систем, повышение активности глутаматергической системы и последующая активация NMDA-рецепторов. Активация NMDA-рецепторов вызывает проникновение ионов кальция внутрь клетки, изменение заряда нейрональной мембраны и последующую гибель клетки. Наиболее вероятно, первые изменения развиваются в дофамин-продуцирующих клетках черной субстанции, затем распространяются на другие стволовые структуры, медиобазальные отделы лобной коры, поясную извилину и далее захватывают кору больших полушарий. Такое развитие нейродегенеративного процесса объясняет в первую очередь низкую продолжительность жизни пациентов (раннее и соответственно наиболее выраженное страдание стволовых структур), развитие при ДТЛ так называемых флюктуаций или колебаний выраженности когнитивных расстройств (поражение восходящих отделов ретикулярной формации) и значительно выраженный дефицит ацетилхолина (поражение как первого, так и второго церебрального ацетилхолинергического пути) [1, 17]. Последняя особенность позволила предположить, что ацетилхолинергические препараты будут при этом заболевании более эффективны, чем при БА [11], что впоследствии было подтверждено в клинических исследованиях.

ДТЛ относится к сенильным деменциям; средний возраст дебюта заболевания составляет 69-70 лет. По данным некоторых авторов [13, 22], ДТЛ чаще страдают мужчины (66\% мужчин и $34 \%$ женщин) в отличие от БА, которой преимущественно болеют женщины. По мнению других исследователей, не отмечается преобладания того или иного пола.

Генетические аспекты ДТЛ тщательно изучались. Особый интерес вызывали возможные мутации паркинов и их связь с развитием ДТЛ. В настоящее время известно одно описание японской семьи, в которой отмечалась мутация паркина 4 - гена, непосредственно кодирующего альфа-синуклеин. При этом в зависимости от тяжести мутации у пациентов развивалась БП или ДТЛ [1]. В настоящий момент это единственное описание генетической терминированной ДТЛ, что не дает основания предполагать, что заболевание является генетически обусловленным.

Наиболее часто ДТЛ дебютирует симптомами паркинсонизма, из которых первыми и наиболее выраженными являются нарушения походки $[4,23,24]$. Пациенты и их родственники обращают внимание на замедление походки, затруднения, возникающие при подъеме с кресла или кровати, при прохождении дверных проемов, выполнении поворотов. Часто при попытке начать движение отмечается топтание на месте. Рано развиваются постуральные нарушения.

Клиническая картина двигательных расстройств при ДТЛ весьма типична и отличается от таковой при БП. Так, паркинсонизм симметричен, тонус выражен весьма мягко, в то время как олиго- и брадикинезия весьма значительны $[17,19,23]$. Тремор отмечается примерно у трети пациентов; чаще развивается постуральный и акционный тремор, нежели тремор покоя. Возможно некоторое преобладание ригидности аксиальной мускулатуры, при этом у пациентов с ДТЛ никогда не формируется разгибательная поза, характерная для пациентов, страдающих супрануклеарным параличом.

Основные проявления паркинсонизма при ДТЛ (сочетание брадикинезии, нарушения ходьбы и постуральных расстройств) характерны и для сочетания БП и деменции. Фактически ДТЛ и БП с деменцией имеют одинаковую картину двигательных расстройств. В связи с этим, как полагает J. Cummings [1], нередко ошибочно диагностируют и то и другое заболевание. Так, при первом обращении к неврологу наиболее вероятным диагнозом будет сочетание БП и деменции, а при первом обращении к психиатру - ДТЛ. Очевидно, что эти заболевания имеют много общего. Очевидно и то, что сочетание БП и деменции может быть результатом ряда патологических процессов и что это не одно заболевание, а скорее всего, группа болезней $[4,21]$. Именно поэтому в диагностике и ДТЛ, и БП следует опираться на диагностические критерии заболевания, в частности анализировать время, которое прошло с момента появления симптомов паркинсонизма до развития деменции.

Когнитивные нарушения при ДТЛ следуют за паркинсонизмом, хотя могут являться и первым признаком заболевания [19, 25, 26]. Наиболее грубо нарушается интеллект, страдает как его операционное звено (способность к обобщению, абстрагированию, семантизации, построению умозаключений), так и регуляция произвольной деятельности (определение цели, построение программы и контроль за ее выполнением). Выражено снижается беглость психических процессов; как правило, этот симптом сочетается с истощаемостью психической деятельности: чем дольше когнитивная нагрузка, тем медленнее и с худшим результатом выполняет задания пациент. Типично выраженное снижение внимания; обсуждается, в какой степени нарушения памяти при ДТЛ являются первичными, т. е. обусловленными нейродегенеративным процессом в медиобазальной лобной коре и гиппокампе, а в какой степени - вторичными, т. е. зависящими от уровня внимания и общей активизации пациента [3, 27]. Афазия нехарактерна для ДТЛ. Зрительно-пространственные расстройства, напротив, выражены весьма значительно и, как правило, больше, чем при любой другой нейродегенеративной деменции такой же степени тяжести. В целом зрительный радикал когнитивных нарушений отмечается при исследовании всех сфер когнитивной деятельности. Так, более низкий уровень внимания при ДТЛ выявлен в отношении графических образов, то же касается и способности к обобщению и выполнению программы при сравнительном предъявлении вербальных и невербальных образов и сравнительном анализе вербальной и невербальной памяти.

Одно из важнейших проявлений ДТЛ - психические нарушения, среди которых преобладают зрительные галлюцинации. Галлюцинации развиваются обычно одновременно с появлением и прогрессированием когнитивных расстройств. Характерны спонтанные галлюцинации, т. е. не обусловленные изменением состояния пациента или приемом лекарственных препаратов. Наряду со спонтанными, крайне высок риск развития медика- 
ментозных галлюцинаций. Так, галлюцинации при ДТЛ являются типичным ответом на терапию противопаркинсоническими препаратами, часто в дозах, не достигающих терапевтических. Именно поэтому при ДТЛ рекомендуется избегать назначения любых препаратов этого ряда, кроме препаратов леводопы. В целом лечение паркинсонизма должно начинаться только тогда, когда двигательные симптомы действительно выражены настолько, что влияют на адаптацию пациента $[1,9]$.

Чаще у пациентов отмечаются истинные, предметные зрительные галлюцинации. В ряде случаев зрительные образы могут сочетаться со слуховыми (пациенты слышат обращенную к ним речь) или тактильными (попытка прикоснуться к ложному зрительному образу дает ощущение фактуры ткани, шерсти и т. д.). Галлюцинации могут быть статичными или движущимися; в таком случае смысл их действий понятен пациенту и детально описывается при беседе с врачом. Характерно уменьшение выраженности или полное исчезновение галлюцинаций при привлечении к ним внимания: так, пациенты часто сообщают, что при попытке прикоснуться к мнимому человеку или животному последние исчезают. Таким образом, галлюцинации при ДТЛ имеют много общего с иллюзорными представлениями (когда предмет принимают за что-либо другое при недостаточном уровне внимания или частичной сенсорной депривации), которые также весьма характерны для ДТЛ. Выраженность галлюцинаций зависит и от степени сенсорной депривации - снижения зрения, его недостаточной коррекции, скудного освещения. В дебюте синдрома галлюцинации единичны, во многом сходны с иллюзиями, возникают только ночью; чаше всего пациент к ним критичен. При дальнейшем развитии галлюцинации заполняют все время бодрствования пациента. Одновременно изменяется соотношение сна и бодрствования, а затем и вовсе утрачивается как физиологический сон, так и физиологическое бодрствование [17]. Когнитивные функции снижаются в значительной степени; пациент перестает самостоятельно ходить, говорит тихо и невнятно; при попытке вступить с ним в контакт быстро истощается. При выходе из галлюциноза пациент частично или полностью забывает события этого времени. Разрешение галлюциноза может быть и спонтанным, т. е. не обусловленным терапией.

Происхождение галлюцинаций при ДТЛ связано с рядом факторов. С одной стороны, галлюцинации - следствие грубого снижения уровня внимания у пациента с выраженными зрительно-пространственными нарушениями. В основе этого симптома может лежать значительное снижение уровня церебрального ацетилхолина. С другой стороны, галлюцинации при ДТЛ - симптом, обусловленный дисфункцией дофаминергических систем, что проявляется снижением уровня церебрального дофамина в сочетании с гиперчувствительностью всех типов дофаминовых рецепторов [6, 17, 18]. E. Perry и соавт. [1] предположили, что субстратом для развития галлюцинаций при ДТЛ является поражение глубинных отделов височных долей с формированием гиперчувствительности ацетилхолиновых рецепторов. В любом случае ясно, что галлюцинации - результат сочетания нескольких патологических процессов. Очевидно также и то, что галлюцинации, развивающиеся на фоне изменения сознания у пациента с изначально выраженными когнитивными нарушениями, не следует считать продуктивной симптоматикой. Более того, лечение ДТЛ, как и продуктивной сим- птоматики, потенциально опасно из-за дальнейшего нарастания выраженности галлюцинаций, а также и для жизни пациента в целом. Известно, что у пациентов с ДТЛ на фоне гиперчувствительности рецепторов к дофамину крайне часто выявляется нейролептический синдром, в том числе в ответ на прием атипичных нейролептиков $[1,17]$.

К дополнительным симптомам, осложняющим терапию ДТЛ, следует отнести периферическую вегетативную недостаточность и изменение цикла сон-бодрствование, отмечающееся не только в галлюцинаторном периоде, как описано ранее, но и на протяжении всей болезни. Результаты исследования, выполненного в 2004 г. у 20 пациентов с ДТЛ, показали, что у половины из них имелась ортостатическая гипотензия [1]. Ранее японские исследователи показали, что сцинтиграфия миокарда с MIBG - веществом, эквивалентным норадреналину и визуализирующим плотность парасимпатических кардиальных окончаний, выявляет кардиальную денервацию у пациентов с ранними проявлениями ДТЛ [28]. Выполненное нами исследование 50 пациентов с вероятной ДТЛ показало во всех случаях наличие кардиальной дизавтономии разной степени выраженности. У половины пациентов отмечалась периферическая вегетативная недостаточность, проявляющаяся преимущественно брадикардией, сухостью кожи и слизистых, непереносимостью жары и ортостатической гипотензией [19]. Интересно, что при развитии галлюцинаций нарастали частота и тяжесть периферической вегетативной недостаточности. Полученные данные позволили предположить, что в развитии психических нарушений при данном заболевании может играть роль и церебральная ишемия, развивающаяся в результате вегетативной недостаточности. О срыве физиологической компенсации свидетельствовало, в частности, то, что пациенты обычно не ощущали снижения АД в положении стоя и часто у них не отмечалось липотимических состояний или обмороков, в то время как давление при ортостатической пробе снижалось более чем на 50 мм рт. ст.

Проведенное позже исследование [29] подтвердило наличие периферической вегетативной недостаточности у пациентов с ДТЛ. Также было показано, что наиболее выраженные изменения происходят в симпатических отделах вегетативной нервной системы, что приводит к относительному преобладанию парасимпатических влияний и может быть основанием для срыва компенсации при изменении состояния пациента или внешних условий. В этом исследовании выявлены также дополнительные проявления кардиальной дизавтономии. При любой, даже незначительной физической активности (попытка встать со стула), у пациентов развивалась суправентрикулярная экстрасистолия, проходящая самостоятельно через 5-10 мин. Подобный симптомокомплекс описан ранее у пациентов с кардиальной дизавтономией на фоне сахарного диабета или перенесенного инфаркта миокарда $[17,29]$. Предполагается, что в основе развития симптома лежит формирование эктопических очагов возбуждения на фоне снижения экстракардиальной регуляции. Показано, что этот симптом наряду с другими проявлениями кардиальной дизавтономии является неблагоприятным прогностическим фактором риска внезапной сердечной смерти у пожилых больных [19, 29].

Диагноз ДТЛ является клиническим, нейровизуализация, как правило, не выявляет специфических признаков 
Таблица 2. Динамика когнитивных нарушений у пациентов исследуемых групп на фоне лечения акатинолом мемантином

\begin{tabular}{|c|c|c|c|c|c|c|c|c|}
\hline Показатель & до лечения & \multicolumn{3}{|c|}{ ДтЛ } & до лечения & \multicolumn{3}{|c|}{$\begin{array}{c}\text { БА } \\
\text { на фоне лечения }\end{array}$} \\
\hline КШОПС, общий балл & $19,9 \pm 5,9$ & $22,7 \pm 2,7$ & $22,8 \pm 2,1$ & $22,3 \pm 4,9$ & $21,3 \pm 3,8$ & $22,8 \pm 1,8$ & $22,8 \pm 1,9$ & $22,7 \pm 6,7$ \\
\hline \multirow{4}{*}{$\begin{array}{l}\text { ШДМ: } \\
\text { внимание } \\
\text { прямой и обратный счет } \\
\text { общий балл }\end{array}$} & & & & & & & & \\
\hline & $28,3 \pm 2,4$ & $36,8 \pm 1,8$ & $36,9 \pm 1,5$ & $37,1 \pm 1,2$ & $29,3 \pm 6,1$ & $32,3 \pm 2,7$ & $32,1 \pm 2,9$ & $32,0 \pm 1,9$ \\
\hline & $5,2 \pm 0,6$ & $7,6 \pm 0,8$ & $7,6 \pm 0,3$ & $7,6 \pm 0,7$ & $5,3 \pm 0,2$ & $6,0 \pm 0,8$ & $6,0 \pm 0,9$ & $5,9 \pm 1,3$ \\
\hline & $109,2 \pm 10,8$ & $119,3 \pm 7,6$ & $119,2 \pm 8,1$ & $119,4 \pm 9,9$ & $108,7 \pm 11,9$ & $118,4 \pm 9,9$ & $118,1 \pm 7,3$ & $116,4 \pm 8,8$ \\
\hline
\end{tabular}

заболевания. Изменения при магнитно-резонансной томографии (МРТ) сходны с таковыми при БА и включают атрофию коры преимущественно височных, теменных и затылочных отделов головного мозга, а также внутреннюю атрофию с расширением боковых желудочков. Возможно наличие перивентрикулярного лейкоареоза, в основном в передних отделах головного мозга, однако его распространенность и выраженность, как правило, невелики. Функциональная визуализация, в частности позитронно-эмиссионная томография (ПЭТ) и магнитно-резонансная спектроскопия (МР-спектроскопия), дает большую информацию. Так, по данным большинства авторов, для пациентов с ДТЛ характерно снижение перфузии и метаболизма в затылочных долях, что не типично для БА. При ПЭТ с 18-флюородопой выявляется более выраженное изменение базальных ганглиев по сравнению с таковым не только при БА, но и при БП $[17,24]$. Таким образом, в сложных случаях проведение ПЭТ и МР-спектроскопии может быть полезным для установления точного диагноза.

Интересны вопросы лечения ДТЛ. Принципы лечения двигательных нарушений распространяются и на другие проявления заболевания. Учитывая полимедиаторный церебральный дефицит и серьезный риск развития осложнений, лечение двигательных и психических расстройств следует начинать только тогда, когда они действительно выражены в такой степени, что нарушают адаптацию пациента, осложняют уход за ним и могут представлять опасность для него и его родственников. В данном случае назначение препаратов целесообразно проводить в стационаре и начинать лечение с минимальных доз.

Препаратами первого ряда при лечении как когнитивных, так и психических расстройств являются ингибиторы ацетилхолинэстеразы. В ряде клинических исследований [1, $17,25]$ показано, что их эффективность в отношении когнитивных функций при ДТЛ выше, чем при БА. Значимый положительный эффект ингибиторов ацетилхолинэстеразы проявлялся в уменьшении выраженности галлюцинаций и бредовых расстройств.

Интересен также эффект другой доказанной симптоматической базовой терапии деменций - антагонистов NMDA-рецепторов. Исследований, посвященных оценке эффективности мемантина при ДТЛ, существенно меньше, чем исследований, касающихся применения при этом заболевании ингибиторов ацетилхолинэстеразы [25]. В связи с этим интересны результаты проведенного нами открытого клинического исследования эффективности акатинола мемантина у пациентов с ДТЛ.
В исследование включено 15 пациентов с вероятной ДТЛ (7 мужчин и 8 женщин) и 15 пациентов с БА (9 женщин и 6 мужчин). Средний возраст больных с ДТЛ - 72,8土3,4 года, пациентов с БА - 65,3 44,9 года. Всем пациентам был назначен акатинол мемантин в дозе 20 мг/сут. Пациенты в группах не различались по возрасту, длительности заболевания и тяжести когнитивных расстройств. Диагноз вероятной ДТЛ устанавливали по критериям Mc Keith и соавт., диагноз вероятной БА по критериям NINCDS-ADRDA, деменции - по критериям DSM-IV и МКБ-10.

Всем пациентам выполняли количественное нейропсихологическое тестирование с использованием краткой шкалы оценки психического статуса (КШОПС, mini mental state examination), батареи тестов для оценки лобной дисфункции (БЛД, frontal assessment battery), шкалы деменции Маттиса (ШДМ), теста рисования часов, тестов для оценки уровня внимания и беглости психических процессов (литеральные и категориальные ассоциации, проба Шульте), теста 5 слов и Бостонского теста называния предметов. Нейропсихологическое тестирование выполняли всем пациентам по стандартному протоколу до и через 2, 4 и 6 мес после начала лечения.

Результаты лечения у пациентов исследуемых групп на фоне монотерапии акатинолом мемантином представлены в табл. 2 и 3. Уже через 2 мес приема акатинола мемантина у пациентов с БА отмечалось достоверное уменьшение выраженности когнитивных нарушений (увеличение общего балла по шкалам КШОПС, $\mathrm{p}=0,033$ и ШДМ, $=0,028)$. Наибольшая положительная динамика наблюдалась в отношении таких симптомов, как ориентация, запоминание материала, прямой и обратный счет $(\mathrm{p}<0,05)$. Отмечалось уменьшение выраженности нарушений внимания, некоторое нарастание беглости психических процессов, улучшение мнестических процессов ( $\mathrm{p}=0,013 ; \mathrm{p}=0,038$ и $\mathrm{p}=0,023$ соответственно). На фоне лечения акатинолом мемантином у пациентов с БА констатировано небольшое, но достоверное снижение выраженности лобной дисфункции $(\mathrm{p}=0,048)$.

Сравнительный анализ эффективности лечения на 2, 4, 6-м месяце лечения акатинолом мемантином при БА не выявил ни позитивной, ни негативной динамики когнитивных нарушений.

У пациентов с ДТЛ через 2 мес лечения акатинолом мемантином установлено достоверное уменьшение выраженности когнитивных нарушений (увеличение общего балла по шкалам КШОПС, p=0,017; ШДМ, p=0,023). Сравнительный анализ отдельных составляющих КШОПС показал, что под влиянием лечения акатинолом мемантином у 
Таблица 3. Динамика когнитивных нарушений у пациентов исследуемых групп на фоне лечения акатинолом мемантином (БЛД)

\begin{tabular}{|c|c|c|c|c|c|c|}
\hline Группа пациентов & \multicolumn{6}{|c|}{ Показатель БЛД } \\
\hline \multicolumn{7}{|l|}{ ДТЛ: } \\
\hline $2 \mathrm{мес}$ & $2,1 \pm 0,8$ & $2,1 \pm 1,2$ & $1,2 \pm 0,6$ & $3,7 \pm 1,8$ & $2,8 \pm 0,7$ & $11,9 \pm 1,8$ \\
\hline 4 мес & $2,2 \pm 0,8$ & $2,2 \pm 0,6$ & $1,2 \pm 0,8$ & $3,6 \pm 1,1$ & $2,9 \pm 0,5$ & $11,8 \pm 1,4$ \\
\hline $6 \mathrm{мес}$ & $2,2 \pm 1,2$ & $2,4 \pm 0,9$ & $1,2 \pm 0,9$ & $3,6 \pm 1,3$ & $2,8 \pm 0,4$ & $11,7 \pm 2,7$ \\
\hline до лечения & $1,6 \pm 1,3$ & $1,4 \pm 0,7$ & $2,0 \pm 1,0$ & $2,3 \pm 0,6$ & $2,9 \pm 0,4$ & $14,7 \pm 1,5$ \\
\hline на фоне лечения: & & & & & & \\
\hline $2 \mathrm{мес}$ & $1,8 \pm 0,8$ & $2,0 \pm 0,8$ & $2,5 \pm 0,6$ & $3,2 \pm 0,9$ & $2,9 \pm 0,8$ & $15,9 \pm 2,3$ \\
\hline $4 \mathrm{mec}$ & $1,7 \pm 1,1$ & $1,9 \pm 0,9$ & $2,3 \pm 0,7$ & $3,5 \pm 1,3$ & $2,8 \pm 0,3$ & $15,8 \pm 1,9$ \\
\hline 6 мес & $1,6 \pm 1,2$ & $1,7 \pm 0,6$ & $2,3 \pm 1,2$ & $3,0 \pm 0,0$ & $2,9 \pm 0,5$ & $15,7 \pm 2,1$ \\
\hline
\end{tabular}

этих пациентов отмечалось достоверное улучшение способности к устному счету $(\mathrm{p}=0,020)$, некоторое улучшение экспрессивной речи $(\mathrm{p}=0,028)$ и уменьшение выраженности зрительно-пространственных расстройств $(\mathrm{p}=0,012)$. При сравнительном анализе показателей ШДМ установлено, что у пациентов с ДТЛ на фоне лечения акатинолом мемантином достоверно улучшились внимание $(p=0,001)$, беглость речи $(\mathrm{p}=0,015)$, способность к прямому и обратному счету $(\mathrm{p}=0,026)$, инициация психической деятельности $(\mathrm{p}=0,011)$, способность к обобщению $(\mathrm{p}=0,008)$, уменьшилась выраженность зрительно-пространственных расстройств $(\mathrm{p}=0,018)$. Несколько в меньшей степени снижалась выраженность мнестических нарушений $(p=0,034)$. Анализ данных шкалы БЛД у пациентов с ДТЛ на фоне лечения акатинолом мемантином свидетельствовал об уменьшении выраженности лобной дисфункции $(\mathrm{p}=0,022)$.

Сравнительная оценка выраженности когнитивных нарушений у пациентов с ДТЛ на 2, 4-м и 6-м месяце лечения акатинолом мемантином показала дальнейшее достоверное уменьшение выраженности когнитивных нарушений. Позитивная динамика проявлялась дальнейшим уменьшением выраженности лобной дисфункции $(\mathrm{p}<0,05)$, зрительно-пространственных нарушений $(\mathrm{p}<0,05)$, увеличением беглости речи $(\mathrm{p}<0,05)$ и нарастанием темпа нейродинамических процессов $(\mathrm{p}<0,05)$.

При сравнительном анализе эффективности терапии акатинолом мемантином у пациентов с ДТЛ и БА отмечено, что под влиянием лечения при БА отмечалась более выраженная позитивная динамика ориентации в пространстве и времени $(\mathrm{p}=0,034)$, мнестических нарушений $(\mathrm{p}=0,022)$, диспраксии $(\mathrm{p}=0,018)$, в то время как при ДТЛ в большей степени улучшились способность к проведению счетных операций $(\mathrm{p}=0,010)$, зрительно-пространственные функции $(p=0,008)$, внимание $(p<0,001)$ и инициация психической деятельности $(\mathrm{p}=0,003)$, беглость речи $(\mathrm{p}=0,015)$, способность к обобщению $(\mathrm{p}=0,019)$ и выстраиванию программы действия $(p=0,035)$.

Анализ возможного влияния терапии акатинолом мемантином на частоту развития и тяжесть галлюцинаций показал, что у пациентов с ДТЛ, принимающих и не принимающих акатинол мемантин, галлюцинации развивались одинаково часто, но выраженность их на фоне лечения была достоверно меньше $(\mathrm{p}=0,012)$.

\section{Клинический пример.}

Больная $\boldsymbol{\Gamma}$., 75 лет, заболевание началось 2 года назад с появления неловкой, шаркающей походки, при ходьбе несколько раз падала вперед без видимых причин. В первые 6 мес болезни присоединились когнитивные нарушения, постепенно прогрессировавшие до степени деменции: нарушилась память, стало труднее ориентироваться в незнакомой обстановке, расплачиваться в магазине за покупки. За месяи до осмотра родственники пациентки обратили внимание на резкое ухудшение когнитивных функций - резко нарастали расстройства памяти, пациентка не осознавала, что она у себя в квартире, была растерянна, практически перестала обслуживать себя, появились зрительные галлюцинации.

При осмотре: пациентка понимает, что находится у врача, но не может объяснить, почему возникла необходимость обращения к врачу, считает себя здоровой. При беседе путается, сообщает, что живет у родственников, хотя на самом деле имеет собственную квартиру. Подробно рассказывает об имеющихся у нее галлюцинациях (видимых объектах), не отдает отчета в их нереальности, растерянна, удивлена их действиями и проникновением в квартиру. Нейропсихологическое тестирование: отмечается умеренная деменция, общий балл КШОПС 18, общий балл ШДМ - 107, общий балл БЛД - 11. В клинической картине деменции преобладают нарушения внимания $и$ инициации психической деятельности, резко снижена беглость речи, отмечается дезориентация. Выявляются мягкие мнестические нарушения со сложностями как запоминания, так и воспроизведения материала после проведения интерферирующего воздействия (кривая запоминания 5 слов 2-3-3-1). Выраженные сложности при выполнении счетных операций и реакции выбора. Умеренные зрительно-пространственные нарушения, пациентка с трудом справляется с простыми заданиями и не способна выполнить тест ориентации линий. В двигательной сфере - легкая гипомимия, тихая речь, очень мягкое симметричное повышение тонуса по пластическому типу в конечностях и аксиальной мускулатуре, брадикинезия при выполнении динамических проб, больше выраженная в ногах. Тремора нет. Несколько затруднено вставание со стула, при попытке встать раскачивается и помогает себе руками. Легкая паркинсоническая согбенность. При оценке постурального ответа выявляются про- и латеропульсии при внешней провокации. Походка шаркающая, мелкими шажками, на широкой базе, затруднены повороты и прохождение дверных проемов. 
Назначена терапия ривастигмином 1,5 мг 2 раза в день, акатинолом мемантином с постепенным подъемом дозы до 10 мг 2 раза в день. Повторный осмотр через 1,5 мес (прием ривастигмина в стабильной дозе 1,5 мес, акатинола мемантина 1 мес): пациентка контактна, ориентирована в месте и времени. Галлюцинаций не отмечается. Эпизод ухудшения состояния, как и предыдущий визит к врачу, полностью забыла. При нейропсихологическом обследовании общий балл КШОПС - 25, общий балл ШДМ - 132, общий балл БЛД - 15. Отмечаются мягкие нарушения внимания, легкие нейродинамические и зрительно-пространственные трудности, мягкая лобная дисфункция, в основном проявляющаяся сложностями при усвоении программы действия. Пациентка полностью адаптирована в быту, обслуживает себя, читает книги, смотрит телевизионные передачи, с удовольствием обсуждает содержание книг и телевизионных программ с врачом. Делает покупки в магазине, не испытывая сложностей при финансовых расчетах. При исследовании двигательной сферы сохраняются мягкая симметричная паркинсоническая ригидность, легкая брадикинезия. Выраженность брадикинезии, как и нарушения ходьбы, уменьшилась. При провокации выявляются мягкие постуральные расстройства, равновесие восстанавливает самостоятельно.
Наблюдение за пациенткой осуществлялось в течение 2 последующих лет. Не зафиксировано эпизодов флюктуации когнитивных нарушений. Состояние пациентки в течение всего времени наблюдения оставалось стабильным, повышения дозы назначенных лекарственных средств или назначения дополнительных препаратов не требовалось.

Таким образом, наше исследование показало, что акатинол мемантин эффективен при когнитивных нарушениях у пациентов с БА и ДТЛ, но действие препарата при этих заболеваниях неодинаково. У пациентов с БА максимальный терапевтический эффект достигался через 2 мес лечения, в дальнейшем отмечалась стабилизация когнитивных нарушений. При ДТЛ позитивное действие акатинола мемантина, проявляясь уже на 2-й месяц лечения, продолжало нарастать. При БА на фоне лечения наибольшая позитивная динамика была характерна для мнестических нарушений, диспраксии и дезориентации, а при ДТЛ - для внимания и инициации психической деятельности, беглости речи и способности к обобщению и выстраиванию программы действия.

Акатинол мемантин не влиял на частоту развития зрительных галлюцинаций при ДТЛ, однако выраженность зрительных галлюцинаций на фоне его приема значительно уменьшалась.

\section{Л И Т E P A T V P A}

1. O’Brien J., Mc Keith I., Ames D. et al. Dementia with Lewy bodies and Parkinson's disease dementia. London: Taylor \& Francis, 2006;264.

2. Kosaka K., Iseki E. Dementia with Lewy bodies. Curr Opin Neurol 1996;9(4):971-5. 3. Ballard C., O'Brien J., Tovee M. Qualitative performance characteristics differentiate dementia with Lewy bodies and Alzheimer's disease. J Neurol Neurosurg Psychiatry 2002;72:565-6.

4. Korczyn A.D. Dementia in Parkinson's disease. J Neurol 2001;248(Suppl. 3):III/1-III/4. 5. Lippa C.F., Smith T.W., Nee L. et al. Familial Alzheimer's disease and cortical Lewy bodies: is there a genetic susceptibility factor? Dementia 1995;6(4):191-4.

6. Mc Shane R., Gedling K., Reading M. et al. Prospective study of relations between cortical Lewy bodies, poor eyesight, and hallucinations in Alzheimer's disease. J Neurol Neurosurg Psychiatry 1995;59(2):185-8.

7. Rezaie P., Cairns N.J., Chadwick A. et al. Lewy bodies are located preferentially in limbic areas in diffuse Lewy body disease. Neurosci Lett 1996;212(2):111-4.

8. Robles A., Rodriguez R.M., Aldrey J.M. et al. Clinical diagnosis of dementia associated with cortical Lewy bodies. Rev Neurol 1995;23(119):62-6.

9. Mc Keith I.G., Galasko D., Kosaka K. et al. Consensus guidelines for the clinical and pathologic diagnosis of dementia with Lewy bodies (DLB): report of the consortium on DLB international workshop. Neurology

1996;47(5):1113-24.

10. McKeith I.G., Ballard C.G., Perry R.H. et al. Prospective validation of Consensus criteria for the diagnosis of dementia with Lewy bodies. Neurology 2001;57:1497-9.

11. Mc Keith I.G., Fairbairn A.F.,

Bothwell R.A. et al. An evaluation of the pre- dictive validity and inter-rater reliability of clinical diagnostic criteria for senile dementia of Lewy body type. Neurology 1994;44(5):872-7. 12. MacKeith I.G., Perry E.C., Perry R.H. Report of the second dementia with Lewy body international workshop: diagnosis and treatment. Consorcium on dementia with Lewy bodies. Neurology 1999;53:902-5.

13. Ince P.G., Mc Arthur F.K., Bjertness E. et al. Neuropathological diagnoses in elderly patients in Oslo: Alzheimer's disease, Lewy body disease, vascular lesions. Dementia 1995;6(3):162-8.

14. L. Knuffman, F. Mohsin, J. Feder et al. Differetiating between Lewy body dementia and Alzheimer's disease: a retrospective brain bank study. JAMDA 2001;146-8.

15. Яхно Н.Н. Когнитивные расстройства в неврологической клинике. Неврол журн 2006;11(Прил. 1):4-12.

16. Яхно Н.Н., Дамулин И.В.,

Мхитарян Э.А. Болезнь Альцгеймера и деменция с тельцами Леви: некоторые аспекты клиники, диагностики и лечения. РМЖ 2003;10(11):567-70.

17. Яхно Н.Н., Преображенская И.С. Деменция с тельцами Леви. Неврол журн 2003;8(6):4-12.

18. Doubleday E.C., Snowden J.S., Warma A.R et al. Qualitative performance characteristics differentiate dementia with Lewy bodies and Alzheimer's disease. J Neurol Neurosurg Psychiatry 2002;72:602-7.

19. Преображенская И.С.

Деменция с тельцами Леви. Дисс. ... докт. мед. наук. М., 2005;367 с.

20. Pellise A., Roig C., Barraquer-Bordas L.I. et al. Abnormal, ubiquitinated cortical neurites in patients with diffuse Lewy body disease.

Neurosci Lett 1996;206(2-3):85-8.

21. Яхно Н.Н., Захаров В.В., Локшина А.Б. и др. Деменции. Рук-во для врачей. 2-е изд.
М.: Медпресс-информ, 2010;272 с. 22. Weiner M.F., Risser R.C., Cullum C.M. et al. Alzheimer's disease and its Lewy body variant: a clinical analysis of postmortem verified cases. Am J Psychiatry

1996;153(10):1269-73.

23. Gnanalingham K.K., Byrne E.J.,

Thornton A. et al. Motor and cognitive function in Lewy body dementia: comparison with Alzheimer's and Parkinson's disease. J Neurol Neurosurg Psychiatry 1997;62:243-52. 24. Ransmayr G., Seppi K., Donnemiller E. et al. Striatal dopamine transporter function in dementia with Lewy bodies and Parkinson's dosease. Eur J Nucl Med 2001;28:1523-8. 25. Преображенская И.С., Мхитарян Э.А., Яхно Н.Н. Сравнительный анализ когнитивных нарушений при деменции с тельцами Леви и болезни Альцгеймера. Журн невропатол и психиатр 2005;105(1):20-5. 26. Del Ser T., Yachinski V., Merskey H. et al. Clinical and pathological features of two groups of patients with dementia with Lewy bodies: effect of coexisting Alzheimer-type lesion load. $\mathrm{Alz}$ dis assoc dis 2001;1(1):31-44.

27. Calderon M., Perry R.J., Erzinclioglu S.W. et al. Perception, attention, and working memory are disproportionately impaired in dementia with Lewy bodies compared with Alzheimer's disease. J Neurol Neurosurg Psychiatry 2001;70:157-64.

28. Yoshita M., Taki J., Yamada M. A clinical role for [123I]MIBG myocardial scintigraphy in the distinction between dementia of the Alzheimer's-type and dementia with Lewy bodies. J Neurol Neurosurg Psychiatry 2001;71:583-8.

29. Тишкова И.Г., Преображенская И.С. Анализ вариабельности сердечного ритма у пациентов с деменцией с тельцами Леви и болезнью Паркинсона. Неврол, нейропсихиатр, психосом 2011;1:46-51. 